\title{
A Lab Experiment on Committee Hearings: \\ Preferences, Power and a Quest for Information
}

\author{
Ju Yeon Julia Park \\ juyeon.park@columbia.edu \\ Adjunct Professor \\ Quantitative Methods in Social Science \\ Columbia University
}




\begin{abstract}
In principle, committees hold hearings to gather and provide information to their principals, but some hearings are characterized as political showcases. This article investigates conditions that moderate committee members' incentives to hold an informative hearing by presenting a game-theoretic model and a lab experiment. Specifically, it studies when committees hold hearings and which types of hearing they hold by varying policy preferences of committee members and the principal and political gains from posturing. Findings provide new insights to how preferences and power distribution affect individuals' incentives to be informed when they make decisions as members of a committee in many contexts.
\end{abstract}

Word count: 10,568 words

Keyword: Experiment, Committee decision-making, Hearing, Information, Posturing 
In many situations, fact-finding committees must give advice to a principal after gathering information via hearings. For example, the committees in legislatures give recommendations to the floor based on information collected from public hearings. Similar public hearing procedures are also found in committees of the United Nations or the European Union (e.g. the European Economic and Social Committee holds public hearings to hear voices from different stakeholders in the region and be consulted with by the EU on economic issues).

However, previous empirical studies suggest that such hearings are sometimes uninformative because the members choose to grandstand by promoting their own views rather than gathering information. ${ }^{1}$ A classic case study by Huitt (1954) finds that committee members only reinforced their predetermined views via hearings on federal price control at the US Senate Committee on Banking and Currency in 1946. Recent examples include hearings at multiple congressional committees on Benghazi terrorists' attacks in 2012. Especially when the then Secretary of State, Hillary Clinton, was subpoenaed, committee members spent more time asking questions in a way that their opinions are emphasized while leaving almost no time for her to provide an answer or even not requiring one (Hersh 2013).

Some recent empirical works investigate under what conditions the information from hearings is actually used in the legislative process. Esterling (2004) finds that the uncertainty and ambiguity in the state of knowledge explain the variance in lawmakers' use and nonuse of expert information in the legislation process based on three case studies. Kasniunas (2009) shows that testimonies from interest groups are more likely to influence markup bills as they work with an ideologically moderate, more bipartisan committee chaired by an inexperienced member of Congress. Kriner and Schickler (2014) demonstrate that even the investigative hearings where members merely grandstand can indirectly affect political landscape by undermining the presidential approval rating if they can secure media coverage. ${ }^{2}$ 
As an extension of this line of research, this article explores additional explanations on when committee members hold informative hearings and when they do not. I specifically analyze committee chairs' decisions to hold hearings, committee members' selection of witnesses, and principals' policy choices. The factors I propose to explain these decisions are the level of policy disagreement between committee members, political gains from posturing in a hearing which is modeled as inviting an advocate as a witness, the chair's power over the selection witnesses, and the principal's policy preference which can operationalize the level of polarization in the final decision-making body (e.g. a legislative floor).

In order to generate testable hypotheses, I present a simple game-theoretic model of hearings and witness selection. While rational choice models on informational theories of committees have made much progress in explaining the information transmission between the floor and committees, the internal decision-making process and political competition within a committee have been largely understudied and extremely simplified (Diermeier and Feddersen 2000; Gilligan and Krehbiel 1987, 1989). Thus, my model highlights the internal decision-making process and competition within a committee.

There are three theoretical features that are distinctive from the existing models. First, most of the previous models consider a committee as a unitary actor rather than a composition of members with different interests, so that internal decision-making processes within a committee have received less attention. ${ }^{3}$ However, I assume a committee of two members with heterogeneous preferences and explicitly models political competition within the committee over the selection of witnesses for a hearing. Second, while previous models did not consider committee members' political incentive to hold a hearing, I assume that committee members earn utility from a hearing not only by collecting information but also by using a hearing to promote their own views. ${ }^{4}$ Lastly and most importantly, while the quality 
of information transmitted from a hearing is exogenously given in most of the previous works, my model endogenizes its level by allowing committee members to choose a set of witnesses endowed with information of varying quality. Thus, the model highlights the discretion that committee members have as information mediators. All these changes allow further investigation of the internal political competition between different stake holders within a committee.

I test the effects of these factors by running a lab experiment that provides important methodological advantages as follows. First, when it comes to analyzing the chair's decision to hold a hearing, observational data does not provide counterfactuals of hearings that a chair decided not to hold. Thus, it is harder to correctly measure the effects of explanatory variables on the chair's decision using observational data. Second, it is extremely difficult to disentangle causal effects of the key variables from all other naturally occurring contexts in which decisions about committee hearings are made. ${ }^{5}$ However, these problems can be best solved by using experimental methods. Since the data is generated under a highly controlled environment, the experiment allows for clear identification of the treatment effects of the key variables by manipulating one factor at a time while holding all other conditions constant. Thus, the strength of this research is high internal validity. ${ }^{6}$

This study uses student subjects, and it is an important aspect of the experimental design. Since students are similar in their age and education level and they did not start their careers or families, these features can minimize unobserved heterogeneity among subjects and enhance internal validity of the study (Kanthak and Woon 2014). Finding empirical support for my theory using student subjects whose behavior is more likely to suffer from bounded rationality suggests that I could have found stronger empirical support if I had used politicians, not only congressmen but also average state legislators, because they are 
generally more sophisticated in their political calculations than students are, and thus their behavior would more closely resemble that of a rational actor assumed in the theory. Therefore, the treatment effects found in the experiment can be considered a lower bound, and the effects may be even larger if the experiment was run on politicians.

The major findings of this article suggest that political polarization can undermine the informativeness of hearings; however, a moderate level of polarization helps some hearings be partially informative by motivating minority members to inform the principal through hearings; interestingly and unexpectedly, when committee members are equally uncertain about the consequences of two policy alternatives, inviting an odd number of witnesses instead of an even number is informationally ideal.

\section{Model}

The basic model setup and assumptions follow Gilligan \& Krehbiel (1987) and Gerling et al. (2005). The procedure of selecting witnesses is a novel addition to the existing literature. Here I present the model using the parameters specified in the experiment. In supporting material, the reader can find a more general version of the model.

There are two possible states of nature $s=\{0,1\}$. The true state of nature is unknown, but there is a common prior belief $P(s=0)=.5$. There are two policy alternatives $x \in\{0,1\}$. There are three strategic actors in the game: the principal $(F)$ and two members of a standing committee, R and B. R serves as a chair of the committee. All players are assumed to maximize von Neumann Morgenstern expected utility.

\section{Model with a Neutral Principal}

The principal prefers implementing a policy that matches the state of the world such that she receives utility of 1 in such a case and 0 otherwise. 


$$
u_{F}(x, s)= \begin{cases}1, & \text { if } x=s \\ 0, & \text { otherwise }\end{cases}
$$

Each committee member earns utility in two ways: policy-based utility and political utility. The policy-based utility, $u_{i}(x, s)$ for $i \in\{R, B\}$, depends on the state of nature, the policy implemented, and their identity as follows:

$$
u_{R}(x, s)\left\{\begin{array} { l l } 
{ 1 , } & { \text { if } x = s = 0 } \\
{ 1 - d , } & { \text { if } x = s = 1 } \\
{ 0 , } & { \text { otherwise } }
\end{array} \quad u _ { B } ( x , s ) \left\{\begin{array}{ll}
1, & \text { if } x=s=1 \\
1-d, & \text { if } x=s=0 \\
0, & \text { otherwise }
\end{array}\right.\right.
$$

$(0 \leq d \leq 1)$

Let $d$ represent the level of disagreement. If $d=0$, both committee members are ex ante indifferent between policy alternatives. However, if $d>0$, they suffer symmetrically from implementing a policy that does not match the state of the world but are rewarded asymmetrically such that $\mathrm{R}$ receives higher utility than his counterpart if $x=s=0$, and $\mathrm{B}$ is rewarded more if $x=s=1$. In this sense, they have conflicting interests, and I refer to the policy 0 as R's favorite or preferred policy and the policy 1 as B's favorite or preferred policy. ${ }^{7}$ The expected policy-based utility is as below:

$$
E\left(u_{i}(x, s)\right)=\sum_{\substack{x \in X \\ s \in S}}\left\{u_{i}(x, s) * P(x \mid s)\right\}, \quad \text { for } i \in\{R, B\}
$$

The political utility, $u_{i}\left(a_{i}\right)$, is simply the number of advocates $\left(a_{i}\right)$ that each individual member invites weighted by a non-negative value of $q$, the marginal benefit of inviting an advocate. ${ }^{8}$ I assume that $q$ is exogenously determined.

$$
\begin{gathered}
u_{i}\left(a_{i}\right)=a_{i} * q, \quad \text { for } i \in\{R, B\} \\
(0 \leq q)
\end{gathered}
$$

Given that each committee member has to pay a cost, fixed at .2 in the experiment, if a hearing is held, ${ }^{9}$ the expected utility function for a committee member when a hearing is held is as follows: ${ }^{10}$ 


$$
E U_{i}=\sum_{s \in X}\left\{u_{i}(x, s) * P(x \mid s)\right\}+u_{i}\left(a_{i}\right)-.2, \quad \text { for } i \in\{R, B\}
$$

The two components of committee members' expected utility provide them with two different motivations when designing a public hearing. Policy utility potentially gives members an information-seeking incentive which depends on the nature of the policy. Some policy issues are resolved through cooperative deliberation (where $d=0$ or is small) while others are resolved through more competitive negotiations (where $d$ is large). If both committee members are ex ante indifferent between policy alternatives, they potentially have a stronger incentive to learn about the state of nature. Otherwise, they may be less interested in doing so.

Political utility gives members a grandstanding motivation to hold a hearing. In public hearings, committee members often appear interested in expressing their own views rather than finding facts. Given that many hearings are open to the public and some receive substantial attention from the media, a member may do so by inviting advocates whose testimony will give support to his policy proposal or by inviting his political opponent as a witness in order to publicly criticize her (as Republicans did to then-Secretary of State Hillary Clinton on terrorists' attack in Benghazi, Libya, at House Foreign Affairs Committee in 2013). In either case, the committee member can enhance his political status and promote his reelection prospects by posturing at hearings because it may help him signal or advertise his political stance to his constituents and facilitate credit claiming for working on the issue. Among his supporters, his grandstanding may be considered representing their voices and thus strengthen the existing support instead of persuading non-supporters. In addition, although grandstanding is uninformative, it may have an agenda-setting power. Hearings on Benghazi terrorists' attack and Hillary Clinton's handling of emails are the examples of such type. Although they did not reveal much of new information, they successfully made the issue 
salient, made her popularity slightly falter and finally made her apologize.

The game starts with an exogenous and nonstrategic nature choosing the state of the world with known probability, .5. Then, the chair decides whether to hold a hearing at the specified cost. If the chair is indifferent, I assume that he randomizes his decision by holding a hearing with .5 probability. If the chair decides to hold a hearing, the chair invites two witnesses and the other committee member invites one witness simultaneously. ${ }^{11}$ Thus, $\mathrm{R}$ represents the majority and $\mathrm{B}$ the minority.

There are three interest groups from which the committee members can invite witnesses. The groups are Red, Blue, and Green. The first two are biased, but the Green group is neutral. When a witness is called, she sends a message supporting either of the two policy alternatives. The witnesses from the Red group always send a message supporting policy 0 . Those from the Blue group always send a message supporting policy 1 . However, those from the Green group send a message that matches the state with probability that is better than flipping a coin. In the experiment, it is fixed at .8 and represents the level of accuracy of the Green witnesses. The information qualities of the different types of witnesses are common knowledge to all players. Witnesses in this game are non-strategic actors.

Substantively, Red witnesses are advocates for R's preferred policy and Blue witnesses are advocates for B's favorite policy. Thus, let the number of Red advocates invited by R be $a_{R}$, and the number of Blue advocates invited by B be $a_{B}$. Similarly, let the number of witnesses invited from the Green group be $g$. Also, let $g_{i}$, for $i \in\{R, B\}$, be the number of Greens invited by the member $i$ such that $g=g_{R}+g_{B}$. Then, R's choice of witnesses will be $g_{R}+a_{R}$, and B's will be $g_{B}+a_{B}{ }^{12}$

At the end of the game, the principal makes a policy decision. If the committee chair decides not to hold a hearing, the principal is uninformed and chooses one of the two policy 
alternatives with equal chances. If a hearing is held, she receives messages from the hearing and updates her belief about the state of nature. Let $p$ be the probability of implementing a policy that matches the true state given the messages from the witnesses.

I assume that the principal is sophisticated enough to know the bias of each information group and the number of witnesses invited from each. Since the principal wants to choose a policy that matches the state, she considers the messages only from the Green group meaningful.

In sum, the timing of the game is as follows:

1. Nature chooses the state of the world with known probability .5 .

2. The chair of the committee decides whether to hold a hearing or not.

3. If a hearing is held, both members of the committee simultaneously select witnesses from three information groups.

4. Each of the selected witnesses sends a public message to the committee members and the principal.

5. With or without a hearing, the principal selects a policy based on the information she has, and payoffs are realized.

Perfect Bayesian Equilibrium is used as a solution concept and will be simply referred to as equilibrium. I present propositions that describe equilibrium strategies and comparative statics using backward induction below. The solutions and proofs are in supporting material.

\section{Policy decision by the principal}

(Proposition PD) Given $m \in\{0,1\}$, suppose that $g_{m}$ is the number of Greens sending a message $m$, such that $g=g_{0}+g_{1}$. If a hearing is held, the principal implements policy 0 if $g_{0}>g_{1}$; policy 1 if $g_{0}<g_{1}$; and policy 0 with .5 probability if $g_{0}=g_{1}$. If a hearing is not held, the principal selects policy 0 with .5 probability. 


\section{Witness selection by committee members}

If a hearing is held, $\mathrm{R}$ chooses two witnesses in any combination of Greens and Reds, while B invites only one witness either from the Green or the Blue group. Let the marginal probability of implementing a policy that matches the state of nature by inviting the $\mathrm{n}^{\text {th }}$ number of one additional Green witness be

$$
\Delta P(n) \equiv P(x=s \mid g=n)-P(x=s \mid g=n-1) .
$$

Interestingly, when $n$ is an even number, the marginal probability is always 0 suggesting that inviting one Green and inviting two Greens produce the same informational effect. $^{13}$ The intuition is as follows. Suppose that a committee has invited two Greens. If they agree, the second Green improves the precision of messages. However, if they disagree, it is not any better than having no Greens. Thus, on average, the second Green does not add any informational benefit ex ante. Therefore, in equilibrium, the total number of Greens invited is either one or three, not two. The marginal probabilities are $\Delta P(1)=.3$ and $\Delta P(3)=.096$. Table 1 presents the members' expected payoffs given their choice of witnesses.

There are three types of pure-strategy equilibria for witness selection which suggest three different types of hearings, respectively. I call these three equilibria Grandstanding (No Greens: NG), Fully informative hearing (All Greens: AG), and Partially informative hearing (Some Greens: SG1 \& SG2).

(Proposition NG) Both $R$ and $B$ do not invite Greens if . $3 *\left(1-\frac{1}{2} d\right) \leq q$.

The comparative statics suggest that as committee members disagree $(d)$ more on policy alternatives and as the political utility of inviting an advocate $(q)$ increases, grandstanding becomes more likely.

(Proposition AG) Both $R$ and B invite only Green witnesses if . $048 *\left(1-\frac{1}{2} d\right) \geq q$.

A fully informative hearing equilibrium is more likely as committee members share 
similar policy preferences $(d)$ and as the political utility of inviting an advocate $(q)$ decreases.

(Proposition SG1) R invites one Green witness, while B does not invite any Green if $.3 *\left(1-\frac{1}{2} d\right) \geq q$

(Proposition SG2) B invites one Green witness, while R does not invite any Greens if $.048 *\left(1-\frac{1}{2} d\right) \leq q \leq .3 *\left(1-\frac{1}{2} d\right)$.

The equilibrium SG1 is mutually exclusive with the equilibrium NG. However, if $.048 *\left(1-\frac{1}{2} d\right) \geq q$, it may coexist with AG. In this case, AG is a Pareto-optimal strategy. ${ }^{14}$ Also, the equilibrium SG2 always coexists only with SG1. Neither of them is Pareto-optimal.

Figure 1 displays the possible equilibria for different values of $q$ and $d$. Committee members are more likely to grandstand as the marginal benefit of inviting an advocate $(q)$ and the level of disagreement $(d)$ increase. However, it is interesting to note that, even at the high levels of disagreement $(d)$, as long as the political utility $(q)$ is small enough, fully or partially informative hearings are possible. Also, the graph marks four experimental treatment conditions which will be explained further in the next section.

\section{Hearing decision by the committee chair}

(Proposition HD) The committee chair holds a hearing if $(p-.5)\left(1-\frac{1}{2} d\right)+a_{R} * q>c$ and randomizes by holding a hearing with .5 probability if $(p-.5)\left(1-\frac{1}{2} d\right)+a_{R} * q=c$.

\section{Model with a Biased Principal}

So far, the principal was assumed to be unbiased. In this subsection, I consider the equilibria in which the principal is biased in favor of the policy preferred by the majority power of the committee. Especially when there are multiple principals as in a legislative floor, this change 
addresses two possible conditions. One is when simple majority rule is used and the median voter is biased instead of being neutral. This condition applies to a legislature where parties are polarized as in the current US Congress. The other is when a supermajority is required to pass a bill so that the pivotal principal takes a more extreme stance than the median principal. In the model, I assume that a biased principal shares the same policy preference as R:

$$
\begin{gathered}
u_{F}(x, s) \begin{cases}1, & \text { if } x=s=0 \\
1-d, & \text { if } x=s=1 \\
0, & \text { otherwise. }\end{cases} \\
(0<d \leq 1)
\end{gathered}
$$

In order to make sure that each committee member is biased toward a certain policy alternative, the level of disagreement $(d)$ is now assumed to be a non-zero positive value. All other assumptions remain the same. Equilibrium solutions and propositions are found in supporting material.

Here, I highlight several interesting equilibrium strategies and comparative statics. First, the principal is more likely to choose policy 0 as she is more biased in favor of the policy. Second, Figure 2 summarizes the equilibrium strategies for witness selection. ${ }^{15}$ The most notable change is that, unlike the case with a neutral principal, there are combinations of $d$ and $q$ with which the only equilibrium is the partially informative SG2. Up to a critical value of $d$, the higher $d$ is, the more likely SG2 is. That is, the fact-seeking incentive of the minority member grows as the principal becomes more biased but limited at a moderate level $\left(d \leq \frac{3}{4}\right)$. However, if the principal is extremely biased $\left(d \geq \frac{3}{4}\right)$, the grandstanding equilibrium (NG) dominates because she will ignore Greens' messages and select policy 0 no matter what. As a result, the marginal utility of inviting a Green decreases, and the committee members just grandstand. 
The following summarizes the most important predictions of the model. First, there are three types of equilibria for witness selection that characterize each of the different types of hearings: grandstanding (NG), partially informative hearings (SG1 and SG2), and a fully informative hearing (AG). Second, in equilibrium, committees invite only an odd number of Greens. Third, with a neutral principal, committee members are more likely to grandstand as they disagree on policy alternatives $(d)$ and as the marginal political benefit of inviting an advocate $(q)$ is high. Fourth, when the principal is moderately biased, the chances of holding a partially informative hearing increase, surprisingly, due to the minority's effort to truthfully appeal to the principal; however, when the principal is extremely biased suggesting an extreme level of polarization, such an effort disappears and the members only grandstand.

\section{Experiment}

The experiment is designed as a three-person game with two committee members, $\mathrm{R}$ and $\mathrm{B}$, and the principal. There are five treatments. The treatments are designed to test the effects of the political benefit of inviting an advocate $(q)$, the level of disagreement between two members of a committee $(d)$, and the neutrality of the principal. Thus, these three conditions vary across the treatments. Table 2 presents the treatments and the equilibrium predictions for the chair's hearing decision and committee members' choice of witnesses. The principal's policy choice is not addressed in the table because it depends on the randomly selected state of nature and messages from witnesses.

The treatments are designed as follows. In the baseline treatment, BASE, committee members neither gain the political benefit from inviting an advocate $(q=0)$ nor have disagreement on an issue $(d=0)$. In the second treatment, BENEFIT, they gain political benefit of inviting an advocate $(q=.2)$. Thus, any differences between the two treatments 
can be attributed to the effect of the political benefit $(q)$. The third treatment, DISAGREE, has the same condition as BENEFIT except that committee members completely disagree over policy alternatives $(d=1)$. Hence, any differences between BENEFIT and DISAGREE can be considered as the effect of the increased level of disagreement $(d)$. The last two treatments, NEUTRAL and BIAS, allow testing the influence of the principal's policy preference. The most important change by having a biased principal is that the committee members grandstand beyond a certain level of disagreement $(d)$ regardless of the benefit of calling an advocate $(q)$. To account for this difference, considering a complete disagreement $(d=1)$, I set the political benefit $(q)$ at .1 , instead of .2 , because if $q=.2$, there is no difference in the equilibrium strategy for witness selection between the model with a neutral principal and that with a biased one. Treatments are marked on Figure 1 and 2.

\section{Procedures}

The experiment was conducted at the Center for Experimental Social Science at New York University using 135 student subjects and was programmed in z-Tree (Fischbacher 2007). At the beginning of the experiment, subjects were randomly assigned to play one of the three roles: $\mathrm{R}, \mathrm{B}$ and the principal that was introduced as $\mathrm{C}$ player to the subjects. The roles, once assigned, did not change throughout the experiment. Nine subjects participated in one session with each role played by three subjects. Subjects experienced only one treatment per session. Each treatment was assigned to three sessions. After an experimenter read instructions to subjects, they were asked to answer a set of questions to check their understanding. The instructions are available as a part of supporting materials.

A period is composed of the following stages. First, each subject was randomly matched with two others such that they form a group of three, R, B and a principal. This 
matching process is repeated every period. Within a group, $\mathrm{R}$ and $\mathrm{B}$ comprise a committee. However, interactions among subjects occurred in an anonymous environment. Second, subjects saw two boxes on their computer screen: Box X and Box Y. The computer randomly selected one of the boxes to hold a prize. Subjects were told that a prize was placed in one of the two boxes with equal chances, but they were not told which box. Third, the chair decided whether to hold a hearing or not. If s/he decided to hold a hearing, $\mathrm{R}$ invited two witnesses and B invited one witness from three information groups, Red, Blue and Green. Subjects were fully informed as to the witnesses' messages as follows: the witnesses from the Red group always said that the prize is in Box X, regardless where the prize is actually located; likewise, those from the Blue group always said that the prize is in Box Y; however, the witnesses from the Green group said the box that truly holds the prize with 80 per cent probability. After selecting witnesses, all three members of a group were revealed the $\mathrm{R}$ and B's choices of witnesses and the summary of messages from the witnesses. At the last stage, the principal decided which box to open. Everyone in the group could see the result of this decision and his or her payoff on the screen. Subjects played this game for 40 periods.

Payoffs are designed in a way that the parameters in the model running from 0 to 1 are scaled up to run from 0 to 100 . For example, when there is no disagreement $(d=0)$, all the subjects received 100 experimental points if they found a prize in any box. When committee members completely disagree with each other $(d=1)$, only the principal received 100 points from finding a prize in any box, and $\mathrm{R}$ and $\mathrm{B}$ received 100 or 0 points depending on which box they found a prize from. Likewise, a committee member earned 20 points per advocate she or he invited if $q=.2$; earned 10 points if $q=.1$. The cost of holding a hearing was 20 points. Subjects earned experimental points in each period but were paid only for the points they earned in five randomly selected periods. In order to prevent earning 
negative payoffs, $\mathrm{R}$ and $\mathrm{B}$ were given 100 extra points in addition to their earnings in the five selected periods. Subjects earned about $\$ 15$ on average including $\$ 5$ as a show-up fee.

\section{Results}

The analysis of the results mainly focuses on the chair's hearing decision and committee members' selection of witnesses. The analysis of the principal's decision can be found in online supporting materials. In order to analyze the chair's decision to hold a hearing, I measure the average rate of holding a hearing for each treatment. If the equilibrium strategy is to hold a hearing, the hearing rate is expected to be 1 ; if it is to randomize the hearing decision, the expected hearing rate is .5. For the committee members' witness selection strategies, I calculate the average number of Greens invited to a hearing for each treatment. For example, it is expected to be 3 when the equilibrium strategy is to invite only the Greens (AG); 1 for some Greens strategies (SG1 or SG2); and 0 for no Greens (NG).

Table 3 presents the expected outcomes and experimental results for each treatment. Since the treatments were assigned at the session-level, the ideal unit of analysis is a session. However, one concern with this approach is that the number of observations for each treatment is only three. As a result, it may lower the statistical power increasing the chances of a Type II error. In order to complement this potential drawback, I additionally conduct a committee-level analysis which takes a decision made in each committee at one experimental period as one observation. The decisions measured at the session-level are marked with $*$ and those measured at the committee-level without. However, the observations within each session may not be independent because subjects interacted with one another. The intra-class correlation (ICC) measures the level of their non-independence and is presented in the table. For hearing decisions, ICCs are small enough to be ignored in all treatments except for BIAS. 
For the selection of witnesses, they are not ignorable in BENEFIT, DISAGREE and NEUTRAL. The differences between the session-level and committee-level measurements are more prominent in standard errors than in actual mean values due to the differences in the number of observations, and in the treatments with the ICCs that are not too small. ${ }^{16}$

I test treatment effects of the three key variables respectively by comparing the outcomes of a pair of treatments that vary only in one variable. First, in order to test the effect of the political benefit of calling an advocate $(q)$, I compare BASE and BENEFIT. The theory predicts that chairs will hold a hearing in both treatments such that the observed hearing rates should not be statistically different from each other. The rates are .94 in BASE and .97 in BENEFIT. To compare the hearing rates, two-sample t-test is used for the session-level analysis. The test shows that the hearing rates are not statistically different from each other as predicted $($ difference $=.03($ s.e. $=.04))$. The result holds in the committee-level analysis for which a two-sample test of proportions is conducted with bootstrapped standard errors clustered by subject with repetition of sampling for 1000 times in order to adjust the nonindependence of an individual subject's decisions. I also estimate bootstrapped standard errors clustered by session, and the results do not change for this pair of treatments and the other pairs to be compared (Results shown in supporting material). Although failing to reject the null is not sufficient evidence for saying that these hearing rates are the same, the standard errors of probabilities in this range are compressed making it easier to find statistically significant difference, which strengthens our confidence in the result.

Committee members are expected to invite one or three Greens (SG1 or AG) in BASE and one Green (SG1 or SG2) in BENEFIT. Therefore, finding more Greens invited to a hearing in BASE than in BENEFIT will empirically support the theoretical prediction that the increase in the political benefit of inviting an advocate $(q)$ leads to inviting more 
advocates than Greens. ${ }^{17}$ The observed average number of Greens in BASE is 2.99 suggesting that subjects played the Pareto-optimal strategy (AG) predominantly in BASE. In BENEFIT, they invited 1.15 Greens on average which is close to the theoretical expectation. In order to test the difference in the average number of Greens invited, I use two-sample t-test for the session-level analysis and the same with bootstrapped standard errors clustered by session for the committee-level analysis in order to correct errors correlated within each session. (Note that since the average number of Greens is measured at the committee-level, it is not feasible to cluster by subject.) The difference is statistically significant yielding support for the prediction: $1.85(.19)$ at the session-level and $1.84(.17)$ at the committee-level. From this point, the test results at the committee-level are reported only when different from those at the session-level.

Additionally, DISAGREE and NEUTRAL also vary only in the value of political benefit of an advocate $(q)$. While the chairs are expected to hold a hearing in both treatments, the hearing rate in DISAGREE is higher (.98) than that in NEUTRAL (.73), and their difference is statistically significant $(.25(.03))$. The chair's decision to hold a hearing is essentially based on the cost-benefit efficiency in a given situation. Since $q$ is twice higher in DISAGREE than in NEUTRAL, holding a hearing might have been less attractive to chairs in NEUTRAL given its cost. Although the point estimate prediction does not reflect this change, subjects seem to have behaved accordingly.

Committee members are expected to invite no Greens in DISAGREE and only one Green in NEUTRAL. As predicted, the average number of Greens invited is greater in NEUTRAL (.7) than in DISAGREE (.4). However, the test shows that they are not distinguishable (.31 (.26)). It seems relevant to the fact that unlike in other treatments, there were notable variations among the sessions in DISAGREE due to some outliers: in one of the 
three sessions an $\mathrm{R}$ member and a B member called a Green, respectively, whenever there was a hearing; in another only one R did the same. All other subjects in all sessions closely followed the equilibrium strategies. In addition, the reason why the average number of Greens in NEUTRAL is smaller than its theoretically expected level may be because the policy disagreement between committee members might have been so salient that they depreciated the informational benefit of a Green, which alarms us about the informationally detrimental effects of political polarization on the legislative decision-making process.

Second, the treatment effect of disagreement $(d)$ between committee members on a policy issue can be tested by comparing DISAGREE to BENEFIT. The theory predicts chairs in both treatments to hold a hearing and committee members to invite no Greens in DISAGREE but one Green in BENEFIT. The hearing rates are .97 in BENEFIT and .98 in DISAGREE, and they are not statistically different from each other (.01 (.03)). The average number of Greens is 1.15 in BENEFIT and .4 in DISAGREE. The difference is slightly insignificant at the session-level $(.75(.28))$ with the p-value at .055 , but it becomes significant at the committee-level $(.76(.25))$. The results indicate that when committee members have diverging policy preferences as opposed to sharing the same set of policy preferences, they tend to invite advocates instead of seeking for unbiased advice from Greens.

Third, the effect of the principal's policy preference can be tested by comparing NEUTRAL and BIAS. The theory predicts that in NEUTRAL, the chair holds a hearing and committee members together invite one Green (SG1 or SG2); in BIAS, the chair randomizes the hearing decision with .5 probability, and committee members invite none of the Greens (NG). The result shows that the average hearing rate is higher in NEUTRAL (.73) than in BIAS (.25) as predicted and the difference is statistically significant $(.48(.12)) .{ }^{18}$ Also, the average number of Greens is greater in NEUTRAL (.70) than in BIAS (.17), and the 
difference is statistically significant $(.54(.17))$. The results suggest that when the principal is completely biased in favor of the majority's preference, a hearing is less likely in the first place, and also, information transmission is largely discouraged in a hearing. This finding also implies the negative effect of political polarization on the informational function of committee hearings.

I now examine the witness selection strategies played most frequently at the committee-level in each treatment. The lower part of Table 3 presents the breakdown of all possible combinations of witnesses invited. Each cell presents the percentage of observations of a particular set of witnesses among all the observations where a hearing was held in each treatment. There are several interesting points. First, in all treatments, the equilibrium strategy or strategies have been played more frequently than any other single strategy that is off-the-equilibrium-path.

Second, in BENEFIT and NEUTRAL where there are two equilibria without a Paretooptimal strategy, SG1 was much more frequently played than SG2. Given that the informational utility that a Green witness provides to all members of a group is nonexcludable and non-rivalrous, inviting a Green can be considered providing public goods to the group. As in these two treatments, when inviting only one Green is expected, the committee member with more power, $\mathrm{R}$, rather than the one with less, $\mathrm{B}$, tends to invite the Green. This finding illustrates that when there is a coordination problem in providing informational public goods to a group and when the principal is unbiased, it is the majority who delivers them. ${ }^{19}$

Third, while no Green is expected in BIAS, SG2 is observed in 24 per cent of the time and SG1 is not. It appears that B sometimes behaved as if the dotted line at the top in Figure2 has been extended beyond the cut-point at $d=.75$, which can be explained by the bounded 
rationality of the subjects playing $\mathrm{B}$ who might have hoped that the principal, by any chance, could consider opening Box Y if they invited a Green and the Green said Box Y held a prize. In DISAGREE, no Green was expected but subjects invited one or two Greens as in BIAS. However, the difference is that in BIAS those who invited Greens are no longer R but B in the minority role. This finding gives support for the theoretical claim that the minority member will invite a neutral witness when the principal is biased and suggests that it is empirically true beyond the theoretically expected level of the principal's bias.

Next, I examine the choice of witnesses by each of the committee members: R and B. Table 4 presents the observed number of Greens measured at both session-level and individual level, and the frequencies of strategies played by each type in each treatment measured in percentages. The total percentage of the periods in which equilibrium strategies were played is provided for each type. Compared to the committee-level analysis, the proportion of equilibrium strategies that were played increased significantly over 80 per cent in most of the treatments, which suggests that off-the-equilibrium strategies at the committeelevel are largely attributed to coordination failures between $\mathrm{R}$ and $\mathrm{B}$.

Since there are multiple equilibrium strategies for each member, it is unclear in which treatment we should expect more (or less) Greens invited either by R or B in order to test the effects of the three treatment variables. For example, inviting two Reds is one of the R's equilibrium strategies in all five treatments; inviting a Blue is B's equilibrium strategy in all five. With this in mind, I will present the paired comparison of treatments to provide an empirical sense of in which treatment conditions each of the $\mathrm{R}$ and $\mathrm{B}$ members invited more Greens on average. For the session-level analysis, I use two-sample t-test. For the individual level analysis, the same test with bootstrapped standard errors clustered by subject is used, and its results are reported if different from those at the session-level. 
First, $\mathrm{R}$ members invited more Greens in treatments that predict $\mathrm{R}$ to invite one or more Greens than not: $\mathrm{R}$ invited more Greens in BASE than in BENEFIT (1.15 (.14)); more in BENEFIT than in DISAGREE (.60 (.18)); more in NEUTRAL than in DISAGREE (.37 (.18)); more in NEUTRAL than in BIAS (.61 (.14)). The differences are statistically significant in all pairs except for the third pair.

Second, B members invited more Greens in BASE than in BENEFIT suggesting the negative effect of political benefit of inviting an advocate on information gathering (.69 (.10)). However, they invited similar number of Greens in the pairs of BENEFIT and DISAGREE (.15 (.16)); DISAGREE and NEUTRAL (.06 (.13)); NEUTRAL and BIAS (.07 (.09)), suggesting that B's strategy does not vary much across treatments except for BASE. The reason is straightforward. Even when one of the committee members was expected to invite a Green in BENEFIT and NEUTRAL, it tended to be $\mathrm{R}$ rather than $\mathrm{B}$. Thus, the average numbers of Greens that B invited in these treatments are not statistically different from those in DISAGREE and BIAS where no Green was expected. However, it is greater in BIAS than in NEUTRAL (.14 (.05)) implying that B member tended to provide information at the cost of his or her advocate when the principal supports the majority's policy preference ex ante.

Figure 3 summarizes R and B members' choices of witnesses with a circular marker for each treatment weighted by the sum of variances of each member's choices. The circles correspond well to the equilibrium number of Greens to be invited at the committee level. BASE almost overlaps the reference point for AG with little variance. BENEFIT and NEUTRAL are between SG1 and SG2 but closer to SG1 implying that R invited a Green more frequently than B did. Since subjects in both treatments experienced a coordination problem, the markers reflect larger variance than any other treatments. DISAGREE and BIAS are located near NG as predicted. 


\section{Empirical Support from Congressional Committees}

Previous works on congressional committees provide direct or indirect support for the major findings of this article. First, party polarization since the 1970s gave rise to a message politics that emphasized position-taking (Devins 2011). In particular, oversight hearings are no longer intended for political reconstruction but are instruments of 'political combat' (Zelizer 2004, 178). Binder $(2003,113)$ quotes former US senator Warren Rudman, who served in the 1980s and early 1990s, saying that the Senate and its committees have worked on more bills since polarization but that most of the increase in works was meaningless posturing that only resulted in partisan gridlock. These observations strengthen my argument that divergent interests within a committee promote members' grandstanding in hearings.

Second, some political and institutional situations such as deficits (Kettl 2002), legislative gridlock (Binder 2003) and divided government (Fiorina 1992) tend to prevent committee members from being productive in policymaking, which increases their relative payoffs from position-taking, and committee hearings are frequently used for this end (Dull and Parker 2012; Fowler and Hill 2006; Parker and Dull 2009, 2013). These findings explain possible determinants of the political gains from posturing and corroborate their effects on the members' behavior in hearings as presented in this article.

Lastly, a study by Evans (1991, 149-150) on the Senate Judiciary Committee, one of the most ideological committees, in the $99^{\text {th }}$ Congress provides an illustrative example of my findings on the behavior of the chair and the minority member under a moderately or extremely biased floor. During that time, the panel of the committee was highly representative of the full chamber and was dominated by Republicans. Thus, for the Democrat ranking minority, Joseph Biden, the best he could do on the issues that were not negotiable was to play dilatory tactics. However, when there is a slight chance of compromise, 
it was frequently Biden, rather than the chair, who sought a compromise. Evans recounts that, 'the chairman was strategically hanging back and waiting for Biden to make the first move,' which strongly corresponds to my findings on the minority member's behavior under a biased floor.

\section{Discussion}

This article examined the conditions under which committee chairs hold hearings and which types of hearings are held by considering committee members' choices of witnesses. Among the findings that are novel to the literature, the most interesting and timely implication of the study is that political polarization, operationalized by the biased principal and the policy disagreement between committee members, can prevent legislative hearings from being informative; however, a moderate level of polarization can help some hearings be partially informative by motivating the minority member to truthfully appeal to the principal through a hearing. Another unexpected and interesting finding is that when committee members are equally uncertain about outcomes of the two policy alternatives, inviting an odd number of witnesses instead of an even number is always optimal.

In addition, in a partially informative hearing where there is a coordination problem over who will provide public goods by inviting an informative witness at the cost of inviting an advocate, it was often the majority member serving the role under a neutral principal while it tends to be the minority under a biased principal. Given that the policy preference of the principal, the floor pivot in a legislature, can capture the level of party polarization on a policy issue, these findings imply that on new and technical issues, for example, it is likely to be the majority party that actively transmits information through hearings. However, on old and socially entrenched issues on which the parties are polarized, it is likely to be the 
minority party because the majority has less incentive to do so. Thus, the result potentially enlightens the audience of such hearings about the different roles that committee members play and the nature of testimonies that may vary depending on the policy types.

The model presented in this article assumed that committee members were incompletely informed about policy consequences prior to holding a hearing. Thus, this study can better explain the hearings held on relatively new and untried policies or old ones when they are "implemented under changing and unpredictable" environments (Gilligan and Krehbiel 1990). It also provides insights to the hearing procedures in medium-range state legislatures which lack informational and institutional resources compared to Congress or a larger state legislature as in California. Furthermore, the assumption is relevant to Curry (2015)'s finding that rank-and-file members and minority members of a committee are often only partially informed about the bill under consideration prior to a hearing because the committee chair intentionally leaves them uninformed in the fear of their opposition to the bill that she or he cares about. While committee members are believed to be fully informed in advance of most congressional hearings that are carefully planned by chairs, the hearings held by those who are unsure about policy outcomes and thus incentivized to gather information from hearings deserve more attention because these are the ones that may function as an informational apparatus originally designed to improve representatives' policy-making abilities.

Given the general design of the study, the findings can be more broadly applied to other similar contexts beyond legislative committee hearings. For example, schools and firms hold hearings before making decisions in order to gather expert information or opinions of students, faculty members, their employees or customers. Wherever there are different stake holders in organizing such hearings and the asymmetry of power between them, the findings 
of this study can explain the behavior of relevant actors and their hearing outcomes.

Overall, this study emphasized a committee's internal decision-making process and political competition between committee members with heterogeneous policy preferences in holding and designing a hearing which have been largely ignored in the previous literature. Theoretically, it was made possible by making more realistic assumptions that a committee is a group of members with competing interests instead of a unitary actor and each member can earn not only policy-based utility but also political utility from a hearing. More importantly, it is the first study that endogenized the level of information transmitted in a hearing by allowing committee members to choose a set of witnesses with information of varying quality. I hope that this work encourages more research to be done on committees' internal decisionmaking processes. A better understanding of how information is collected and how policy decisions are made in specialized committees through political competition will help us better institutionalize decision-making bodies in many contexts.

Ju Yeon Julia Park <juyeon.park@columbia.edu> is Adjunct Professor of Quantitative Methods in Social Science at Columbia University, Institute for Social and Economic Research and Policy, 420 West 118th Street, Suite 807, Mail Code 3355, New York, NY 10027. 
Table 1. Payoffs for committee members from the selection of witnesses

\begin{tabular}{lcc}
\hline R member $\mid$ B member & Green & Blue \\
\hline Green-Green & $-.448 d+.896$ & $-.4 d+.8$ \\
& $-.448 d+.896$ & $q-.4 d+.8$ \\
\hline Green-Red & $q-.4 d+.8$ & $q-.4 d+.8$ \\
& $-.4 d+.8$ & $q-.4 d+.8$ \\
\hline Red-Red & $2 q-.4 d+.8$ & $2 q-.25 d+.5$ \\
& $-.4 d+.8$ & $2 q-.25 d+.5$ \\
\hline
\end{tabular}

*Upper entry of each cell is payoff for R member; lower entry for B member.

*Note that the cost of hearing has been omitted from each payoff. 
Figure 1. Equilibrium for Witness Selection with a Neutral Principal

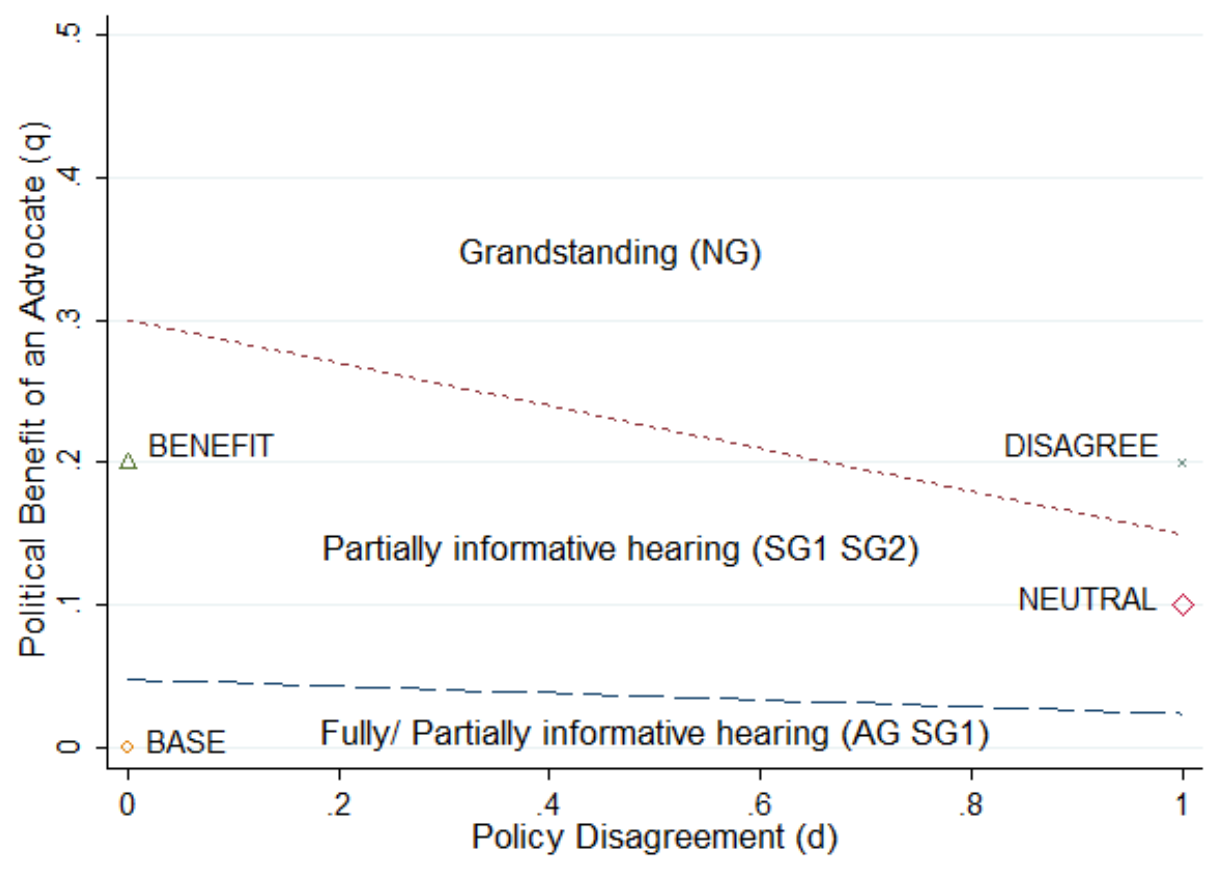

*Two dashed lines divide the equilibrium space. Markers denote experimental treatments. 
Figure 2. Equilibrium for Witness Selection with a Biased Principal

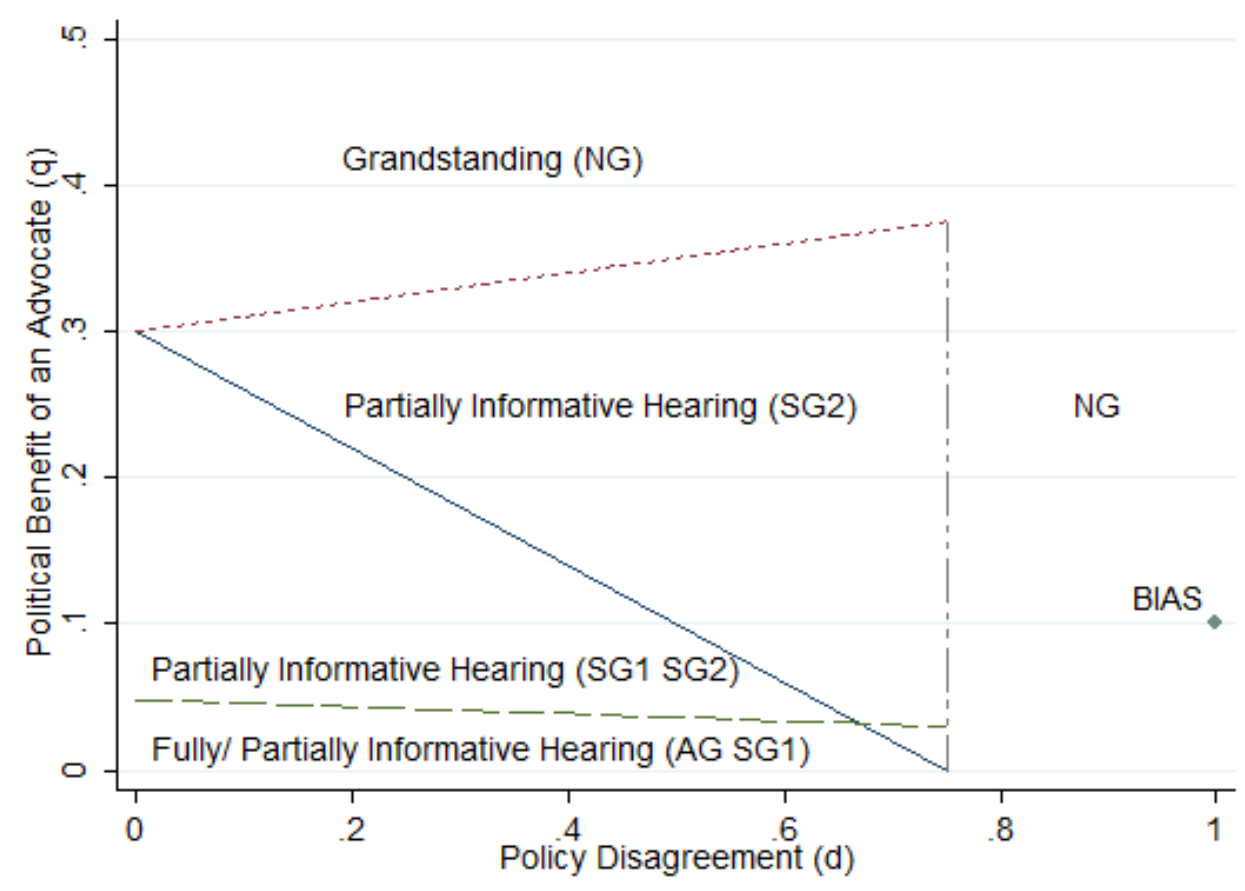


Table 2. Summary of Treatments and Predictions

\begin{tabular}{llllll}
\hline Treatment & $\begin{array}{l}\text { Political } \\
\text { Benefit }(\boldsymbol{q})\end{array}$ & $\begin{array}{l}\text { Disagree- } \\
\text { ment }(\boldsymbol{d})\end{array}$ & Principal & \multicolumn{2}{c}{ Equilibrium Strategy } \\
\cline { 5 - 6 } & 0 & 0 & Neutral & Hold & $\begin{array}{l}\text { All Green }(\mathrm{GG}, \mathrm{G}) \\
\text { Some Green }(\mathrm{GR}, \mathrm{B})\end{array}$ \\
\hline BASE & .2 & 0 & Neutral & Hold & $\begin{array}{l}\text { Some Green1 (GR, B) } \\
\text { Some Green2 (RR, G) }\end{array}$ \\
\hline DISAGREE & .2 & 1 & Neutral & Hold & No Green (RR, B) \\
\hline NEUTRAL & .1 & 1 & Neutral & Hold & $\begin{array}{l}\text { Some Green1 (GR, B) } \\
\text { Some Green2 (RR, G) }\end{array}$ \\
\hline BIAS & .1 & 1 & Biased & $\begin{array}{l}\text { Hold } \\
\text { or Not }\end{array}$ & No Green (RR, B) \\
\hline
\end{tabular}


Table 3. Expected and Observed Hearing Rates and Witness Selection

\begin{tabular}{|c|c|c|c|c|c|}
\hline Treatment & BASE & BENEFIT & DISAGREE & NEUTRAL & BIAS \\
\hline$q$ & 0 & .2 & .2 & .1 & .1 \\
\hline$d$ & 0 & 0 & 1 & 1 & 1 \\
\hline Principal & Neutral & Neutral & Neutral & Neutral & Biased \\
\hline & \multicolumn{5}{|c|}{ Hearing } \\
\hline EQ strategy & Yes & Yes & Yes & Yes & Randomize \\
\hline Expected rate & 1 & 1 & 1 & 1 & .5 \\
\hline Observed rate* & $.94(.04)$ & $.97(.03)$ & $.98(.01)$ & $.73(.02)$ & $.25(.25)$ \\
\hline Observed rate & $.94(.01)$ & $.97(.01)$ & $.98(.01)$ & $.73(.02)$ & $.25(.02)$ \\
\hline $\mathrm{ICC}$ & $.06(.07)$ & $.05(.05)$ & $.01(.02)$ & $.00(.01)$ & $.19(.16)$ \\
\hline \multirow[t]{2}{*}{ Obs. } & 360 & 360 & 360 & 360 & 360 \\
\hline & \multicolumn{5}{|c|}{ Witness selection } \\
\hline \multirow[t]{2}{*}{ EQ strategy } & $\mathrm{AG}$ & SG1 & $\mathrm{NG}$ & SG1 & NG \\
\hline & SG1 & SG2 & & SG2 & \\
\hline Expected \# of G & 1 or 3 & 1 & 0 & 1 & 0 \\
\hline Observed \# of $\mathrm{G}^{*}$ & $2.99(.01)$ & $1.15(.19)$ & $.40(.21)$ & $.70(.15)$ & $.17(.08)$ \\
\hline Observed \# of G & $2.99(.01)$ & $1.15(.04)$ & $.39(.03)$ & $.70(.04)$ & $.24(.05)$ \\
\hline $\mathrm{ICC}$ & $.00(.01)$ & $.16(.14)$ & $.35(.23)$ & $.16(.14)$ & $.00(.04)$ \\
\hline Obs. & 339 & 348 & 353 & 263 & 91 \\
\hline & \multicolumn{5}{|c|}{ Proportional breakdown of the invited witnesses (\%) } \\
\hline NG $(R R, B)$ & 0 & 18.68 & 63.17 & 34.22 & 75.82 \\
\hline SG1 $(\mathrm{GR}, \mathrm{B})$ & $\mathbf{0}$ & 41.95 & 19.55 & 43.73 & 0 \\
\hline $\mathrm{SG} 2(\mathrm{RR}, \mathrm{G})$ & 0 & 9.20 & 11.33 & 2.66 & 24.18 \\
\hline $\mathrm{GR}, \mathrm{G}$ & 0 & 18.1 & 4.25 & 7.22 & 0 \\
\hline GG,B & 0 & 8.33 & 0 & 1.52 & 0 \\
\hline $\mathrm{AG}(\mathrm{GG}, \mathrm{G})$ & 99.71 & 3.74 & 0 & 0 & 0 \\
\hline Other & .29 & 0 & 1.7 & 10.65 & 0 \\
\hline EQ Total $(\%)$ & 99.71 & 51.15 & 63.17 & 46.39 & 75.82 \\
\hline
\end{tabular}

* The observed hearing rates and the observed number of Greens with * signs are measured at the session level. For all other entries, the unit of observation is a decision made in one committee in one period. Standard errors are in parentheses. ICC refers to intra-class correlation which measures the correlation among the observations within each session.

* Entries of equilibrium strategies are in bold. For the equilibrium strategies of witness selection, AG refers to All Greens; SG Some Greens; NG No Greens. GR,G means that R invited one Green and one Red while B invited one Green. The similar notation applies to GG,B. Other refers to the observations in which the R invited a Blue or B invited a Red. 
Table 4. Choice of witnesses by individual committee members (\%)

\begin{tabular}{|c|c|c|c|c|c|}
\hline Treatment & BASE & BENEFIT & DISAGREE & NEUTRAL & BIAS \\
\hline$q$ & 0 & .2 & .2 & .1 & .1 \\
\hline$d$ & 0 & 0 & 1 & 1 & 1 \\
\hline Principal & Neutral & Neutral & Neutral & Neutral & Biased \\
\hline EQ strategy & $\mathrm{AG}$ & SG1 & NG & SG1 & NG \\
\hline & SG1 & SG2 & & $\mathrm{SG} 2$ & \\
\hline \multicolumn{6}{|c|}{$\mathbf{R}$ member } \\
\hline R's EQ strategy & $\begin{array}{l}\text { GG, GR } \\
\text { or RR }\end{array}$ & GR or RR & RR & GR or RR & RR \\
\hline Observed \# of $\mathrm{G}^{*}$ & $1.99(.01)$ & $.84(.14)$ & $.24(.12)$ & $.61(.14)$ & $0(-)$ \\
\hline Observed \# of G & $1.99(.01)$ & $.84(.03)$ & $.24(.02)$ & $.60(.03)$ & $0(-)$ \\
\hline $\mathrm{RR}$ & 0 & 27.87 & 74.79 & 41.83 & 100 \\
\hline GR & $\mathbf{0}$ & 60.06 & 23.8 & 56.27 & 0 \\
\hline GG & 99.7 & 12.07 & 0 & 1.9 & 0 \\
\hline EQ total $(\%)$ & 99.7 & 87.93 & 74.79 & 98.1 & 100 \\
\hline \multicolumn{6}{|c|}{ B member } \\
\hline B's EQ strategy & B or $\mathrm{G}$ & B or $\mathrm{G}$ & B & B or $G$ & B \\
\hline Observed \# of $\mathrm{G}^{*}$ & $1(.00)$ & $.31(.09)$ & $.16(.13)$ & $.10(.02)$ & $.17(.08)$ \\
\hline Observed \# of G & $1(.00)$ & $.31(.02)$ & $.16(.02)$ & $.10(.02)$ & $.24(.05)$ \\
\hline B & 0 & 68.97 & 84.14 & 79.47 & 75.82 \\
\hline $\mathrm{G}$ & 100 & 31.03 & 15.58 & 9.89 & 24.18 \\
\hline EQ total (\%) & 100 & 100 & 84.14 & 89.36 & 75.82 \\
\hline \multicolumn{6}{|c|}{ other entries, the unit of observation is the strategy played by an individual committee } \\
\hline \multicolumn{6}{|c|}{ member ( $\mathrm{R}$ or $\mathrm{B}$ ) in one period. Standard errors are in parentheses. Entries for equilibrium } \\
\hline \multicolumn{6}{|c|}{ strategies are in bold. For R member's strategies, RR means that R member invited two Reds; } \\
\hline \multicolumn{6}{|c|}{ GR means one Green and one Red; and GG means two Greens. For B member's strategy, B } \\
\hline \multicolumn{6}{|c|}{ means that B member chose a Blue; $G$ a Green. The rest of the cases omitted from the table } \\
\hline
\end{tabular}


Figure 3. Individual Level Witness Selection Weighted by Variances

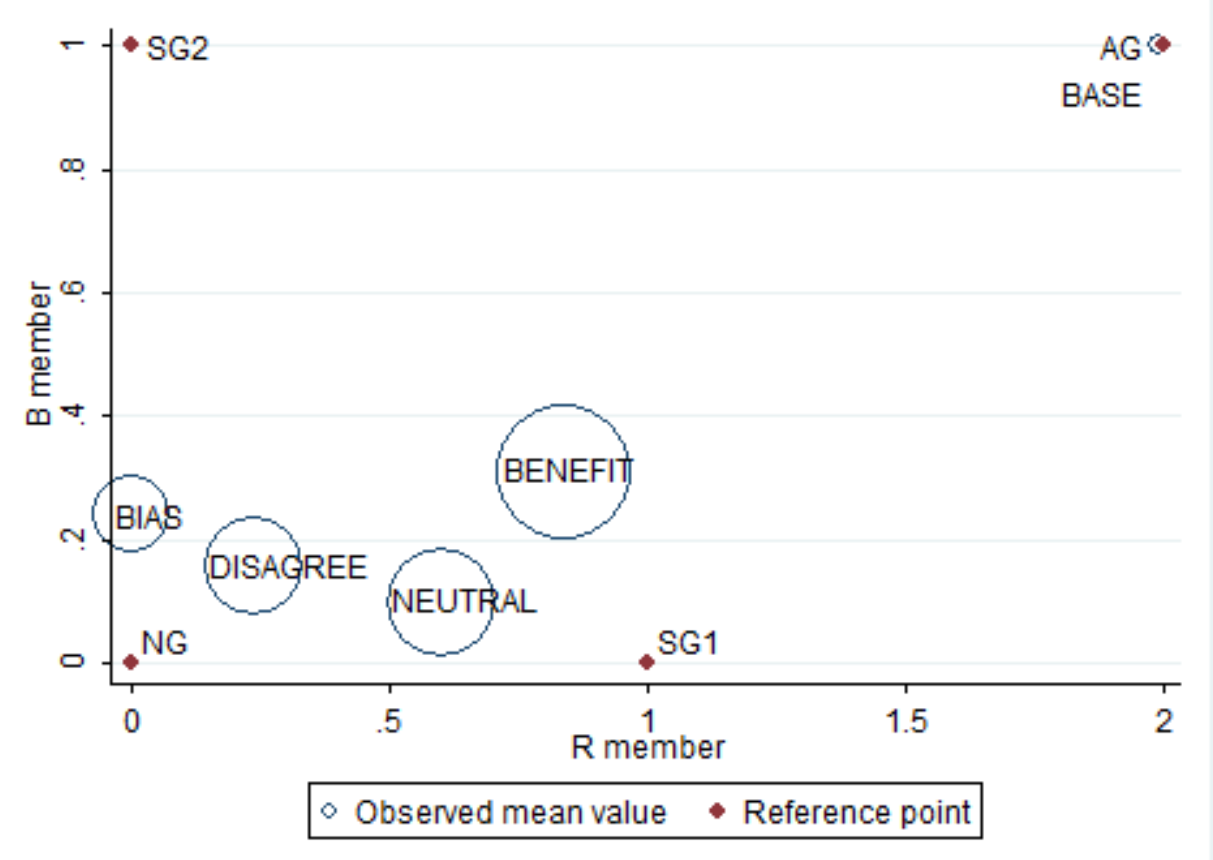

*Circular markers report the average number of Greens invited in each treatment. Dots indicate reference points for the equilibrium strategies in one or multiple treatments. 


\section{References}

Battaglini, Marco, Salvatore Nunnari and Thomas Pelfrey. 2012. "Legislative Bargaining and the Dynamics of Public Investment." American Political Science Review 106 (2): 407-29.

Binder, Sarah. 2003. Stalemate. Washington, DC: Brookings Institution.

Curry, James M. 2015. Legislating in the Dark: Information and Power in the House of Representatives. Chicago, IL: University of Chicago Press.

DeGregorio, Christine. 1992. "Leadership Approaches in Congressional Committee Hearings." The Western Political Quarterly 45 (4): 971-83.

Del Sesto, Steven L. 1980. "Conflicting Ideologies of Nuclear Power: Congressional Testimony on Nuclear Reactor Safety.” Public Policy 28 (1): 39-70.

Devins, Neal. 2011. "Party Polarization and Congressional Committee Consideration of Constitutional Questions." Faculty Publications. Paper 1235. http://scholarship.law.wm.edu/facpubs/1235 (Accessed 26 March 2015).

Diermeier, Daniel and Timothy J. Feddersen. 2000. "Information and Congressional Hearings." American Journal of Political Science 44 (1): 51-65.

Dull, Matthew and David C.W. Parker. 2012. "Congressional Oversight: Overlooked or Unhinged?” APSA's Legislative Studies Section, Extension of Remarks, 1-6.

Esterling, Kevin M. 2004. The Political Economy of Experitse. Ann Arbor, MI: University of Michigan Press.

Farnsworth, David N. 1961. Senate Committee on Foreign Relations. Urbana, IL: University of Illinois Press.

Fehrler, Sebastian and Niall Hughes. 2014. "How Transparency Kills Information Aggregation: Theory and Experiment." http://www2.warwick.ac.uk/fac/soc/economics/research/workingpapers/2015/twerp 1057_hughes.pdf (Accessed 26 March 2015).

Fiorina, Morris P. 1992. Divided Government. New York: Macmillan Publishing.

Fiorina, Morris and Charles Plott. 1978. "Committee Decisions under Majority Rule." American Political Science Review 72:575-98.

Fischbacher, Urs. 2007. "Zurich Toolbox for Readymade Economic Experiments, Experimental Economics." Experimental Economics 10 (2): 171-8.

Fowler, Linda L., and Seth J. Hill. 2006. "Guarding the Guardians: U.S. Senate Oversight of Foreign and Defense Policy, 1947-2004." Paper presented at the Annual Meeting of the American Political Science Association, Philadelphia, PA, 30 August- 3

September. 
Gerling, Kerstin, Hans Peter Grüner, Alexandra Kiel and Elisabeth Schulte. 2005.

"Information Acquisition and Decision Making in Committees: A Survey."

European Journal of Political Economy 21: 563-597

Gilligan, Thomas W. and Keith Krehbiel. 1987. "Collective Decision Making and Standing Committees: A Collective Choice Rationale for Restrictive Amendment Procedures.” Journal of Law, Economics, and Organization 3 (2): 287-335.

Gilligan, Thomas W. and Keith Krehbiel. 1989. "Asymmetric Information and Legislative Rules with a Heterogeneous Committee.” American Journal of Political Science 33 (2): 459-90.

Gilligan, Thomas W. and Keith Krehbiel. 1990. "Organization of Informative Committees by a Rational Legislature.” American Journal of Political Science 34 (2): 531-64.

Goeree, Jacob K. and Leeat Yariv. 2011. "An Experimental Study of Collective Deliberation.” Econometrica 79 (3): 893-921.

Hersh, Joshua. 2013. "Clinton Benghazi Hearing by The Numbers: So Many Questions, So Little Answer Time." Huffington Post, January 28, 2013.

http://www.huffingtonpost.com/2013/01/28/clinton-benghazihearing_n_2568439.html, (Accessed 26 March 2015).

Huitt, Ralph K. 1954. "The Congressional Committee: A Case Study.” American Political Science Review 48 (2): 340-65.

Jones, Bryan D., Frank R. Baumgartner and Jeffery C. Talbert. 1993. "The Destruction of Issue Monopolies in Congress.” American Political Science Review 87 (3): 657-71.

Kanthak, Kristin and Jonathan Woon. 2014. "Women Don't Run? Election Aversion and Candidate Entry." American Journal of Political Science 00 (0): 1-18.

Kasniunas, Nina T. 2009. "Impact of interest group testimony on lawmaking in Congress." $\mathrm{Ph} . D$. diss. Loyola University Chicago. http://ecommons.luc.edu/luc_diss/220 (Accessed 26 March 2015).

Kennedy, Carole. 2003. "Gender Difference in Committee Decision-making: Process and Outputs in an Experimental Setting." Women \& Politics 25: 27-45.

Kettl, Donald F. 2002. Deficit Politics: The Search for Balance in American Politics. Longman.

King, David C. 1997, Turf Wars: How Congressional Committees Claim Jurisdiction. Chicago: University of Chicago Press.

Krehbiel, Kieth. 1986. "Sophisticated and Myopic Behavior in Legislative Committees: An Experimental Study.” American Journal of Political Science 30: 542-61.

Kriner, Douglas L. and Eric Schickler. 2014. "Investigating the President: Committee Probes and Presidential Approval, 1953-2006.” The Journal of Politics 76 (2): 1-14. 
Landa, Dimitri and Dominik Duell. "Social Identity and the Nature of Electoral Representation.” American Journal of Political Science. Forthcoming.

Levy, Gilat. 2007. "Decision Making in Committees: Transparency, Reputation, and Voting Rules." American Economic Review 97 (1): 150-168.

Lutzker, Paul. 1969. "The Behavior of Congressmen in a Committee Setting: A Research Report." The Journal of Politics 31 (1): 140-66.

Miller, Gary and Joe Oppenheimer. 1982. "Universalism and Majority Rule Committees." American Political Science Review 76 (3): 561 - 75.

Morrow, William L. 1969. Congressional Committees. New York: Charles Scribner's Sons.

Morton, Rebecca B. 1993. "Incomplete Information and Ideological Explanations of Platform Divergence.” American Political Science Review 87(2): 382-92.

Parker, David C.W. and Matthew Dull. 2009. "Divided We Quarrel: The Politics of Congressional Investigations, 1947-2004.” Legislative Studies Quarterly 34: 319-45.

Parker, David C.W. and Matthew Dull. 2013. "Rooting Out Waste, Fraud, and Abuse: The Politics of House Committee Investigations, 1947 to 2004.” Political Research Quarterly 66 (3): 630-44.

Prat, Andrea. 2005. "The Wrong Kind of Transparency." American Economic Review 95(3): 862-77.

Redman, Eric. 1973. The Dance of Legislation. New York: Simon and Shuster.

Sachs, Richard C. 2004. "Hearings in the U.S. Senate: A Guide for Preparation and Procedure." Congressional Research Service (CRS) Report for Congress. http://assets.opencrs.com/rpts/RL30548_20030819.pdf (Accessed 26 March 2015).

Scher, Seymour. 1960. "Congressional Committee Members as Independent Agency Overseers: A Case Study.” American Political Science Review 54: 911-20.

Truman, David B. 1951. The Governmental Process: Political Interests and Public Opinion. New York, NY: Alfred A. Knopf.

Woon, Jonathan. 2012. "Laboratory Tests of Formal Theory and Behavioral Inference." In Experimental Political Science: Principles and Practices, ed. Bernhard Kittel, Wolfgang J. Luhan, and Rebecca B. Morton. New York: Palgrave Macmillan, 54-71.

Zelizer, Julian E. 2004. On Capitol Hill: The Struggle to Reform and Its Consequences, 19482000. Cambridge: Cambridge University Press.

For comments and suggestions on earlier versions of this article, I give especial thanks to Rebecca Morton, Eric Dickson, Jonathan Woon, Sean Gailmard, Stephane Wolton, Chris 
Dawes, Kristin Kanthak, and Stephen Chaudoin. I also thank Frances Lee and three anonymous referees for their very helpful comments. This research was financially supported by the Center for Experimental Social Science at New York University.

1 See DeGregorio 1992; Del Sesto 1980; Farnsworth 1961; Huitt 1954; Jones, Baumgartner, and Talbert 1993; Lutzker 1969; Morrow 1969; Redman 1973; Sachs 2004; and Truman 1951 for empirical evidences.

${ }^{2}$ Note that none of these works use formal language to theoretically explain such conditions.

${ }^{3}$ Gilligan and Krehbiel (1989) consider a committee with two heterogeous members. However, in their model internal decision-making processes are not addressed and information qualities available to committee members are exogenously determined whereas in my model committee members can choose the quality of information they acquire.

4 A strand of literature considers committee members with career concerns. These models assume that committee members' payoffs are not related to making a right decision on policies but to showing principals that they are competent types (Fehrler and Hughes 2014; Levy 2007; Prat 2005). The members' incentive in models in this literature is different from the political incentive in my model. Moreover, these models assume information qualities available to committee members are exogenously determined whereas in my model committee members can choose the quality of information they acquire.

${ }^{5}$ Examples include a committee chair's personality and experience, the separation of powers, the pattern of party control, party polarization, institutional variation in the oversight mandates of committees, and timing of hearings within a presidential administration.

${ }^{6}$ Lab experiments have been used to study elite behavior in numerous works on legislative committee decision-making process (Battaglini, Nunnari and Pelfrey 2012; Fiorina and Plott 1978; Krehbiel 1986; Miller and Oppenheimer 1982), gender differences (Kanthak and Woon 
2014; Kennedy 2003), candidate positioning (Morton 1993) and representation (Landa and Duell, Forthcoming). Given that both lab experiments and formal theories have limitations in real-world validity of artificial environment (Woon 2012), the findings of this article and the aforementioned works complement rather than substitute the existing and future research using observational data.

7 This preference design follows the utility function of committee members with conflicting preferences presented in Gerling et al. (2005) which is a review paper and Goeree and Yariv (2011). One difference is that their model also includes a case in which a member prefers one policy over the other regardless of the state of the world. However, for the parsimony of the model, I choose not to include this strong partisan case because its inclusion only generates the predictions that are similar to what is available in the current model.

8 An advocate may also refer to an opponent whom a committee member wishes to publicly criticize. However, I will call both types of witnesses advocates. Basically, the action of inviting an advocate captures the member's political incentive to participate in a hearing, that is, to grandstand.

${ }^{9}$ If a hearing is held the committee members have to invest their time and resources to search for witnesses, issuing invitations, and paying witnesses' travel costs. Also, there are opportunity costs because, given their time and budget constraints, the committee members could have spent their resources for other activities.

${ }^{10}$ If a hearing is not held, the expected utility is simply the expected utility of policy-based utility such that $E U_{i}=E\left(u_{i}(x, s)\right)$, for $i \in\{R, B\}$.

11 The number of witnesses to be invited can be considered a budget constraint, since committees have constraints on time and money to spend on a hearing. It is always binding because there is no cost of inviting additional witnesses and the utility of the committee 
members is increasing in witnesses. The reason for restricting the number of witnesses to be invited to three instead of other numbers is because it is the smallest possible number with which the chair can select more witnesses than the other member. Thus, it allows the equilibrium solution to be as simple as possible and provides the most control to the experimenter by giving only the minimum number of choices to subjects to choose from. I assume that the minority invites one witness instead of none because the minority party's right to select witnesses is protected by RULE XI 2.(j)(1) in the House and Rule XXVI paragraph $4(\mathrm{~d})$ in the Senate.

12 In equilibrium, $\mathrm{R}$ does not call Blue witnesses and vice versa. That is because R's strategy to call a Blue is strongly dominated since the message does not help the principal learn about the state and only contributes to benefiting B as long as $q>0$.

${ }^{13}$ When $g$ is an odd number, the marginal probability of implementing a policy matching the state of nature is positive but decreases as more Greens are invited. However, when $g$ is an even number, it is always 0 . Thus, if $g$ can be any positive integer, $P(x=s \mid g=1)=$ $P(x=s \mid g=2)=.8$ and $P(x=s \mid g=3)=P(x=s \mid g=4)=.896$, and so on. This is a surprising feature of the discrete choice combined with a majoritarian rule. However, this feature holds only if each of the two states of nature is believed to be equally likely.

14 As in Table 1 , the expected utility for both members is $-.448 d+.896$ if AG is played and $q-.4 d+.8$ if SG1; the former is greater than the latter if $.048 *\left(1-\frac{1}{2} d\right) \geq q$.

15 Note that the intercepts remain the same as in Figure 1 for a neutral principal. Also, although it is not shown in Figure 2, each equilibrium exists for certain range of $d$ when $q=0$ : AG exists if $\frac{63}{64} \leq d \leq 1$; SG1 if $\frac{15}{16} \leq d \leq 1$; and SG2 if $\frac{22}{25} \leq d \leq 1$.

16 Despite the small ICC, the observed average number of Greens in BIAS is much smaller 
when measured at the session-level. That is because a session with zero average number of Greens had significantly less number of hearings compared to other sessions, but the sessionlevel measurement weighted the average number of Greens in each session equally.

17 In BASE, AG is Pareto-optimal, and it was played predominantly. Therefore, testing if more Greens were invited in BASE than in BENEFIT on average is appropriate.

18 A similar amount of drop in the hearing rate in BIAS as in NEUTRAL can be partially due to the low level of $q$ as well, but another possibility could be that $\mathrm{R}$ might have been altruistic so that $\mathrm{R}$ tried to prevent $\mathrm{B}$ from earning negative payoffs by not holding a hearing. It is especially plausible because $\mathrm{R}$ is indifferent between holding and not holding a hearing in this treatment.

19 It is also important to note that, in BENEFIT and NEUTRAL, the evidence of coordination failure is most frequently observed in two ways: no Greens (NG) or two Greens. One possible reason for the failure is that, even if each individual committee member has played one of his equilibrium strategies in a given treatment, the committee's decision as a whole may end up with an off-equilibrium strategy. For example, if R invited a Green and a Red and B invited a Green so that two Greens were invited, then it is a simple coordination failure. However, if two Greens were invited because $\mathrm{R}$ invited two Greens and B invited a Blue, the blame goes to R's non-equilibrium move rather than a coordination failure. However, individual level analysis shows that $\mathrm{R}$ invited two Greens for 12 per cent of the time in BENEFIT and 1.9 per cent in NEUTRAL. That is, in most cases, both $\mathrm{R}$ and B played equilibrium strategies. 